\title{
Aspergillus fumigatus antigens
}

\author{
R. López-Medrano, M. C. Ovejero, J. A. Calera, P. Puente and F. Leal
}

Author for correspondence: F. Leal. Tel: +3423294400 ext. 1947. Fax: + 3423267970.

e-mail: fleal@gugu.usal.es

Departamento de Microbiología y Genética and Instituto de Microbiología Bioquímica, Universidad de Salamanca/Consejo Superior de Investigaciones Cientificas, 37007 Salamanca, Spain
Cytosolic fractions of mycelial extracts from Aspergillus nidulans, A. flavus, and three different isolates of $A$. fumigatus, grown to stationary phase in Czapek-Dox-AOAC medium, were tested by immunoblotting for the presence of antigens reactive to $\mathbf{8 0}$ serum samples from aspergilloma patients. Fifty control serum samples were used to determine the specificity of the reactions. In the A. fumigatus cytosolic fraction a group of four main antigenic bands (p90, p60, p40 and p37) was consistently recognized (in total or partial form) by $90 \%$ of the serum samples from the aspergilloma patients. This group of antigens was designated as the 'cytosolic fraction complex' (CFC). As confirmed by two-dimensional electrophoresis followed by immunoblotting with aspergilloma serum samples, each of the four antigenic bands is formed of several isoforms of acidic glycopeptides with slightly different pls. All the isoforms are at least $\boldsymbol{N}$-glycosylated, as demonstrated by endoglycosidase $\boldsymbol{H}$ removal of a considerable amount of sugar residues. The relationship of these antigens with certain other $A$. fumigatus antigens previously reported in the literature, and their potential use in the immunodiagnosis of aspergilloma, are discussed.

Keywords: Aspergillus, aspergilloma, immunodiagnostics, fungal antigens

\section{INTRODUCTION}

The standardization of antigenic mixtures (mainly from Aspergillus fumigatus) reactive to serum samples from patients with different forms of aspergillosis has been a primary goal for researchers involved in the immunodiagnosis of these diseases. Complex preparations have been successfully used to detect different classes (IgG and $\mathrm{IgE}$ ) of specific antibodies by several methods including immunodiffusion, immunoelectrophoresis, RIA, ELISA and BALISA (Kurup \& Kumar, 1991; Andriole, 1992). The antigens present in these mixtures were in their native form and the molecules directly responsible for the immune reactions were identified indirectly by subsequent analytical procedures. High-resolution techniques such as SDS-PAGE, analytical isoelectrofocusing and twodimensional electrophoresis have also been applied to the analysis of these complex mixtures. However, to our knowledge, only the separation power of SDS-PAGE has been combined with the specificity of immune reactions in Western blot assays to define with better precision which particular molecules are responsible for the reaction with the specific antibodies from aspergillosis-affected indi-

Abbreviation: CFC, cytosolic fraction complex. viduals (Burnie et al., 1989; Hearn et al., 1990; Fratamico \& Buckley, 1991; Latgé et al., 1991; Hearn, 1992; Kobayashi et al., 1993). Because of the need to establish an integrated approach to the identification of defined Aspergillus antigens, the current study was undertaken. In this work we have tried to combine the best of the different previous approaches: (i) standardization of antigenic mixtures with reference to the selected species (Kim \& Chaparas, 1979; Burnie et al., 1989; Hearn, 1992), isolates, growth conditions (Kim \& Chaparas, 1978; van der Heide et al., 1985a, b; Calera et al., 1994), subcellular fractions and extraction methods; (ii) the use of SDSPAGE, and two-dimensional electrophoresis methods, followed by immunoblotting to analyse in depth the composition of the antigenic mixtures; (iii) the use of a high number of serum samples, perfectly documented, from clinical situations or control patients. Using these approaches, we have been able to detect and unequivocally identify useful antigens in the previously analysed extracts.

\section{METHODS}

Organisms and growth conditions. Three Aspergillus fumigatus isolates were used: $\mathrm{AFC}$ is a strain from the American Type Culture Collection (ATCC 9197). AFR is a clinical isolate from 
the sputum of a patient with pulmonary aspergilloma; AFN was isolated from a lung biopsy of a patient with invasive pulmonary aspergillosis and AIDS, kindly provided by J. M. TorresRodriguez (IMIM, Barcelona, Spain). Aspergillus nidulans G1059wt (adF17 pabaA1 yA2) was obtained from A. J. Clutterbuck, Glasgow, UK. Aspergillus flavus, isolated from a lymphadenopathy in a patient with breast cancer and cutaneous invasive aspergillosis was a gift from A. del Palacio (12 de Octubre Hospital, Madrid, Spain).

The organisms were maintained on solid YED medium [1\% $(\mathrm{w} / \mathrm{v})$ D-glucose, $1 \%(\mathrm{w} / \mathrm{v})$ Difco yeast extract and $2 \%(\mathrm{w} / \mathrm{v})$ agar]. To obtain high yields of conidia, the fungi were grown on solid Aspergillus complete minimal medium or on AMM [0.1\% glucose, $0.6 \% \mathrm{NaNO}_{3}, 0.052 \% \mathrm{MgSO}_{4}, 0.052 \% \mathrm{KCl}, 0.15 \%$ $\mathrm{KH}_{2} \mathrm{PO}_{4}$, traces of $\mathrm{FeSO}_{4}$ and $\mathrm{ZnSO}_{4}$, and $1.5 \%(\mathrm{w} / \mathrm{v})$ agar $(\mathrm{pH} 6 \cdot 5)]$. Plates were incubated at $28^{\circ} \mathrm{C}$ for at least $4 \mathrm{~d}$.

For liquid growth cultures, Bacto Czapek-Dox broth/Bacto Synthetic broth AOAC (1:1) (CDA) medium was used (obtained from Difco). As shown in our previous studies on the influence of the culture medium on the presence of antigens specifically reactive to Aspergillus extracts (Calera et al., 1994), Czapek medium seems to strongly induce the biosynthesis of CFC antigens. For $A$. nidulans, CDA medium, both solid and liquid, was supplemented with $10 \mathrm{mg} p$-aminobenzoic acid and $200 \mathrm{mg}$ adenine per litre.

All the Aspergillus species were grown by inoculation of $10^{5}$ conidia $\mathrm{ml}^{-1}$ in 1-litre Erlenmeyer flasks containing $300 \mathrm{ml}$ of the corresponding liquid medium followed by incubation at $37^{\circ} \mathrm{C}$ in an Adolph Kühner orbital shaker at 280 r.p.m. Mycelia were harvested from liquid medium cultures by filtering through Whatman GF/C paper and washed thoroughly with double-distilled $\mathrm{H}_{2} \mathrm{O}$. The wet cake was immediately frozen and kept at $-70^{\circ} \mathrm{C}$ until used.

Preparation of cytosolic extracts. Frozen mycelia were thawed and mixed with lysing buffer $[100 \mathrm{mM}$ Tris $/ \mathrm{HCl} \mathrm{pH} 7.5$ containing $1 \mathrm{mM}$ EDTA, $5 \mathrm{mM}$ dithiothreitol, $1 \mathrm{mM}$ freshly added phenylmethylsulfonyl fluoride (PMSF, Sigma) $5 \mu \mathrm{g}$ Aprotinin $\mathrm{ml}^{-1}$, and $5 \mu \mathrm{g}$ Pepstatin $\mathrm{A} \mathrm{ml} \mathrm{m}^{-1}$ (both from Boehringer Mannheim)] to give a dense suspension. Samples were then distupted in a French press (SLM Aminco) using the 20000 p.s.i. (138 MPa) cell, previously refrigerated at $-20^{\circ} \mathrm{C}$, at a pressure of 16000 p.s.i. (110 MPa). Complete breakage was monitored by microscopy. Broken mycelia were centrifuged at $150000 \mathrm{~g}$ for $1 \mathrm{~h}$ to pellet cell-walls and total membranes; the resulting supernatant was considered as the cytosol. For SDSPAGE, cytosolic fractions were extracted by boiling in $2 \%$ (w/v, final concentration) SDS, clarified $(20000 \mathrm{~g}$ for $30 \mathrm{~min}$ ) and stored as described above. Protein was quantified by a modification of the Lowry method (Peterson, 1977). Extracts containing less than $1 \mathrm{mg}$ protein $\mathrm{ml}^{-1}$ were concentrated by precipitation with 7 vols cold acetone at $-70^{\circ} \mathrm{C}$ for at least $3 \mathrm{~h}$. Precipitated protein was pelleted by centrifugation for $20 \mathrm{~min}$ at $12000 \mathrm{~g}$ at $4{ }^{\circ} \mathrm{C}$, dried in a vacuum evaporator (Savant instruments), carefully resuspended in $2 \% \mathrm{SDS}$ to the desired concentration and clarified by centrifugation at $20000 \mathrm{~g}$ for $30 \mathrm{~min}$.

Treatments with endoglycosidase $\mathbf{H}$. After acetone precipitation, a dry sample of cytosol was solubilized in buffer $[50 \mathrm{mM}$ sodium citrate $\mathrm{pH} 5.5$ supplemented with $\beta$-mercaptoethanol $(0 \cdot 1 \mathrm{M}$, final concentration) and a $1 \cdot 2$-fold excess of SDS relative to total protein concentration]. The sample was heated at $100^{\circ} \mathrm{C}$ for $3 \mathrm{~min}$. After cooling the sample, $1 \mathrm{mU}$ endoglycosidase $\mathrm{H}$ (endo- $\beta-N$-acetylglucosaminidase $\mathrm{H}$ from Streptomyces plicatus, Boehringer Mannheim) was added per $\mu$ g protein, and $0.5 \mathrm{mM}$
PMSF (final concentration) was added to prevent proteolytic degradation. The mixture was then incubated at $37^{\circ} \mathrm{C}$ for $24 \mathrm{~h}$.

SDSPAGE. Electrophoreses were carried out on a Protean II or Mini-Protean apparatus (Bio-Rad) on isotropic $14 \%$ or $16 \%$ $(\mathrm{w} / \mathrm{v})$ acrylamide slab gels $(16 \times 18 \times 0.1 \mathrm{~cm}$ or $8 \times 6 \times 0.1 \mathrm{~cm})$ using the discontinuous buffer system of Laemmli (1970). Molecular mass protein standards were Bio-Rad Low Molecular Weight standards. Proteins in gels were detected by a sensitive silver stain (Morrisey, 1981) or by staining for $30 \mathrm{~min}$ with $0.5 \%$ Coomassie Brilliant Blue R-250 in acetic acid/2propanol/water $(1: 3: 6$, by vol.) and destaining in acetic acid/methanol/water (10:5:85, by vol.).

Two-dimensional gel electrophoresis. Two-dimensional gel electrophoreses were performed as described by Bravo (1984) and O'Farrell (1975). Briefly, the first-dimension separations for resolving acidic proteins were done on $150 \times 2.3 \mathrm{~mm} 4 \%(\mathrm{w} / \mathrm{v})$ polyacrylamide gels containing $6 \%(\mathrm{w} / \mathrm{v})$ ampholytes $(2 \%$

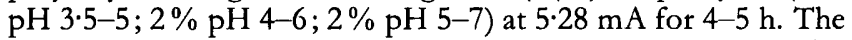
second-dimension separations were carried out in a $16 \%(\mathrm{w} / \mathrm{v})$ SDS-polyacrylamide gel $(20 \times 14.5 \mathrm{~cm})$ and electrophoresed at room temperature overnight. Carbamalyte $2 \mathrm{D}$ standards (carbamylated creatine phosphokinase and carbonic anhydrase, Pharmacia) were used as internal markers.

Human serum samples. A total of 130 human serum samples was provided by microbiology laboratories of different Spanish hospitals. Eighty of these serum samples were from aspergilloma cases. Aspergilloma was demonstrated by chest X-ray changes showing a discrete lesion with a halo and positive cultures for $A$. fumigatus obtained repeatedly either from sputum cultures or by bronchoscopy. The serological response against Aspergillus antigens was demonstrated by immunodiffusion tests with commercial antigens, showing at least three precipitating arcs against $A$. fumigatus mycelial or culture filtrate antigens. Fifty serum samples were used as controls : 28 were from healthy individuals (blood donor bank), 17 from asthmatic and cystic fibrosis patients and five from pulmonary tuberculosis cases. No antibodies against Aspergillus antigens were detected in these sera, using the same immunodiffusion tests as described above.

Electrophoretic blotting procedures and immunological detection of proteins. Proteins from extracts were first subjected to electrophoresis (SDS-PAGE or two-dimensional) as described and then transferred to nitrocellulose sheets $(0.45 \mu \mathrm{m}$; Schleicher \& Schuell) in a Trans-Blot cell (Bio-Rad) as previously described (Calera et al., 1994).

Glycoprotein detection. Protocol B of the DIG glycan detection kit (Boehringer Mannheim) was used according to the manufacturer's instructions.

Photography. Stained gels were photographed with a 32 Asa black-and-white Panatomic-X (Kodak) film using an orange (Coomassie stain) or blue (silver stain) filter. Nitrocellulosedeveloped blots were photographed with an orange filter or with no filter.

\section{RESULTS}

\section{Identification of $\boldsymbol{A}$. fumigatus polypeptides highly reactive in immunoblots with sera from aspergilloma patients}

Cytosolic fractions from $A$. nidulans, $A$. flavus and three isolates of $A$. fumigatus grown to stationary phase in Czapek-Dox-AOAC (CDA) medium were separated by SDS-PAGE and analysed by silver staining and by immunoblotting using aspergilloma serum samples. The 


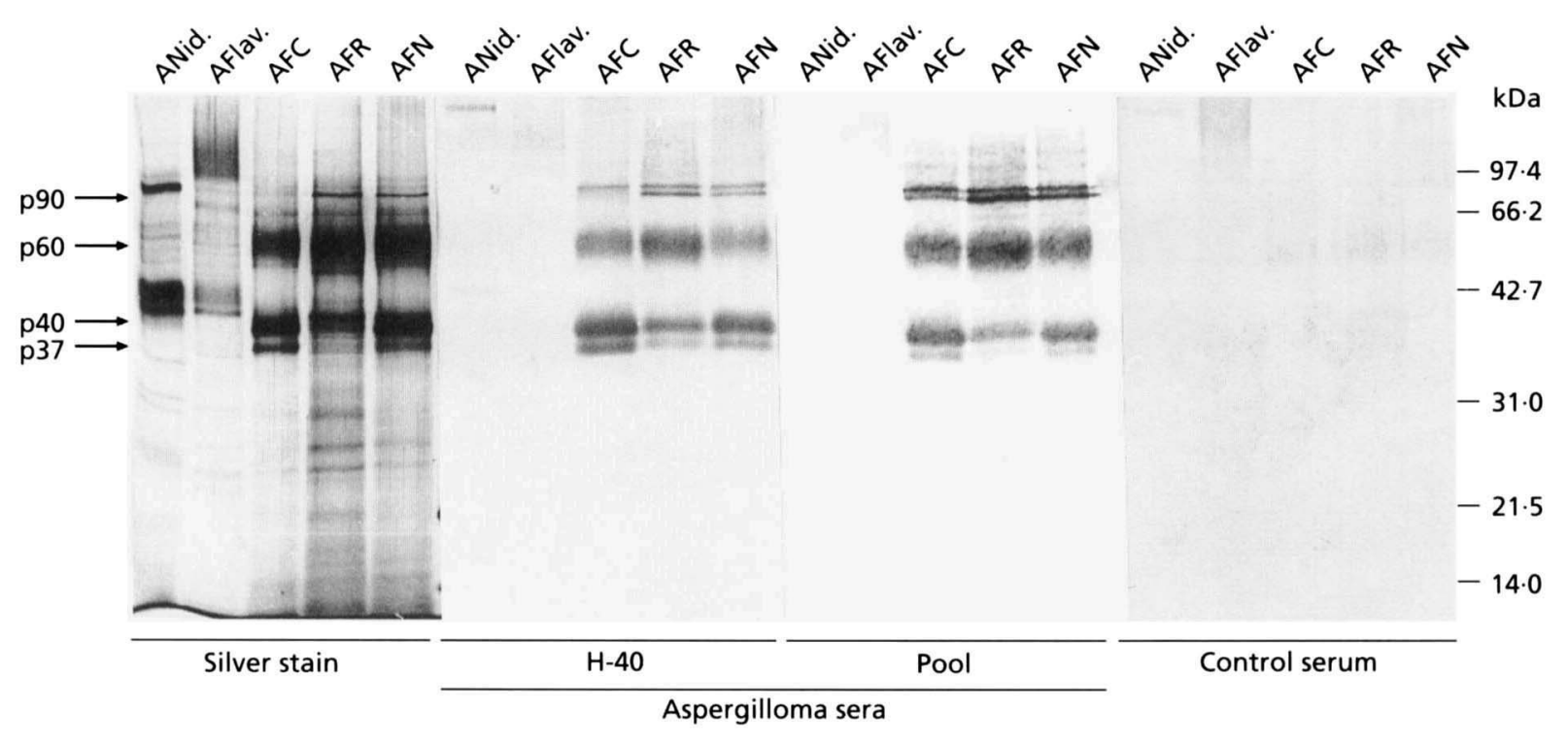

Fig. 1. SDS-PAGE $(16 \%, w / v)$ of the cytosolic fractions from three Aspergillus species grown with shaking at 280 r.p.m. in Czapek-AOAC medium for $7 \mathrm{~d}$ at $37^{\circ} \mathrm{C}$ (initial inoculum $10^{5}$ conidia $\mathrm{ml}^{-1}$ ). The separated proteins were either silver stained $(4 \mu \mathrm{g}$ protein per lane) or transferred to nitrocellulose paper ( $20 \mu \mathrm{g}$ protein per lane) and probed with the following human sera at $1 / 250$ dilution: $\mathrm{H}-40$, a representative aspergilloma serum sample; Pool, a pool of 10 different aspergilloma sera; and Control serum, a representative serum sample of healthy blood-bank donors. Lanes: ANid., $A$. nidulans; AFlav., A. flavus; AFC, AFR and AFN, three different isolates of $A$. fumigatus (see Methods).

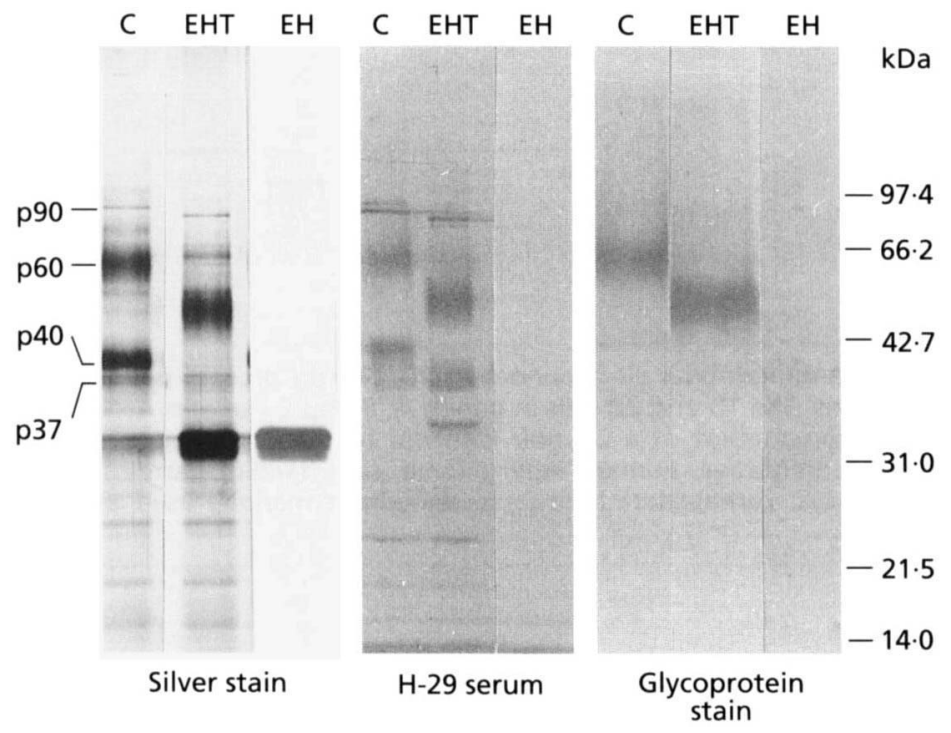

Fig. 2. SDS-PAGE $(16 \%, w / v)$ and Western blots of native and endoglycosidase $H$ treated cytosol of $A$. fumigatus isolate AFR. Lanes: C, native cytosol; EHT, cytosol after digestion with endoglycosidase $\mathrm{H}(1 \mathrm{mU}$ per mg protein); $\mathrm{EH}$, control endoglycosidase $\mathrm{H}$. The gel was stained with silver nitrate (left panel) and the blots were either stained for glycoproteins (DIG-glycan detection kit, Boehringer-Mannheim; right panel) or probed with a human aspergilloma serum sample (1/250, H-29; middle panel). silver-stained polypeptide pattern (Fig. 1) was quite similar for the cytosolic fractions from $A$. fumigatus (AFC, AFR, AFN), but characteristic for each fraction. $A$. nidulans (AN) and $A$. flavus (AFL) gave completely different patterns. Fig. 1 shows that the major silverstained polypeptides in cytosolic fractions from $A$. fumigatus were also the most reactive antigens to specific IgG antibody from a representative serum sample (H-40) or a pool at 10 different aspergilloma sera ( $1 / 250$ dilution). $A$. flavus and $A$. nidulans did not show any consistent reaction.
When nitrocellulose blots identical to the one just described were reacted with 130 different serum samples, the responses to 80 serum samples from aspergilloma patients were similar to that shown in Fig. 1. In all cases, the cytosolic fraction of the three $A$. fumigatus isolates was the most consistently reactive. We designated the group of the four main reactive bands, with apparent molecular masses of $90,60,40$ and $37 \mathrm{kDa}$, as CFC (cytosolic fraction complex). From this point these proteins will be named $\mathrm{p} 90, \mathrm{p} 60, \mathrm{p} 40$ and $\mathrm{p} 37$. fumigatus polypeptide antigens. Of the 80 aspergilloma sera, $53 \%$ recognized all 

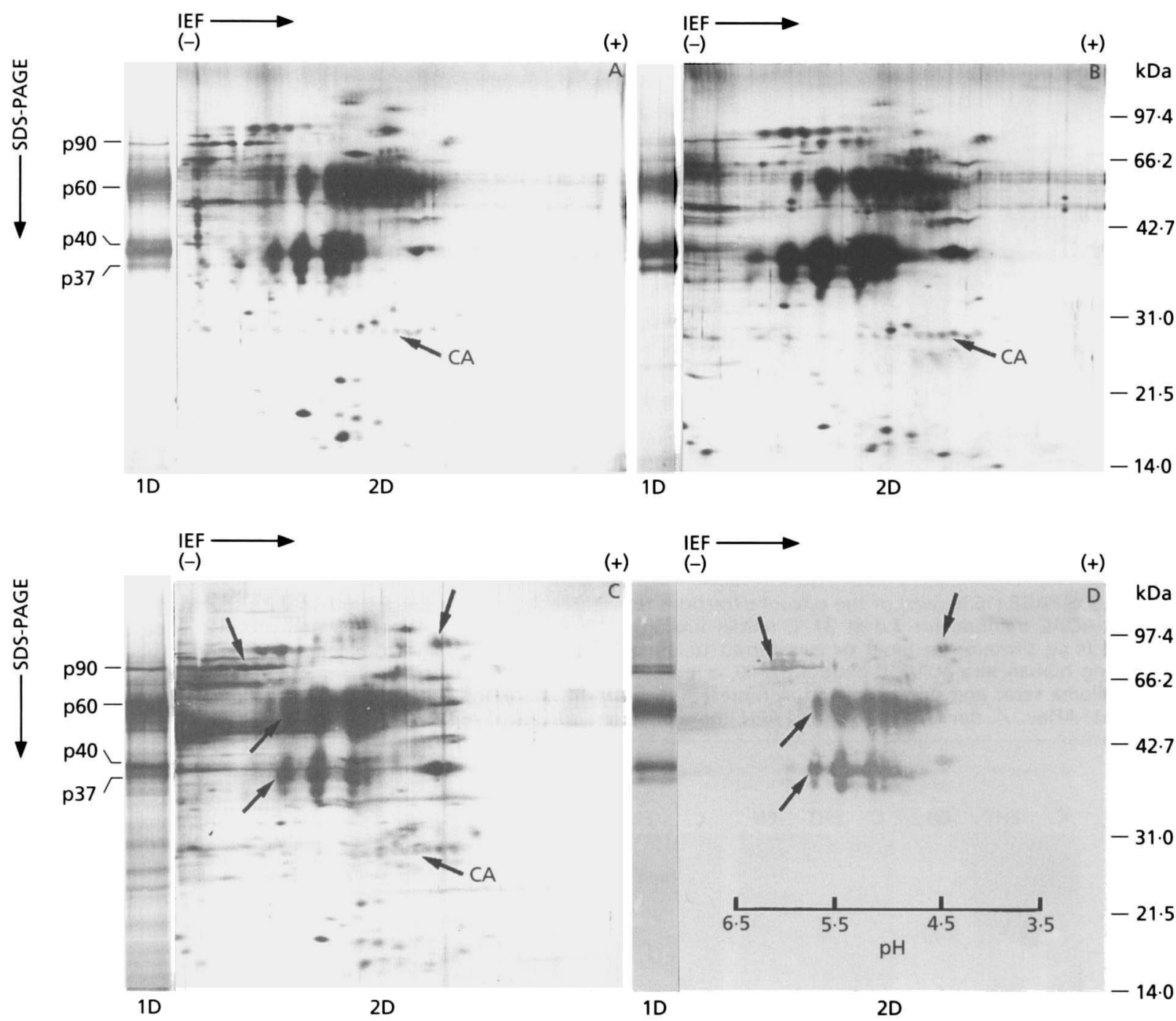

$(+)$

IEF

$(+)$

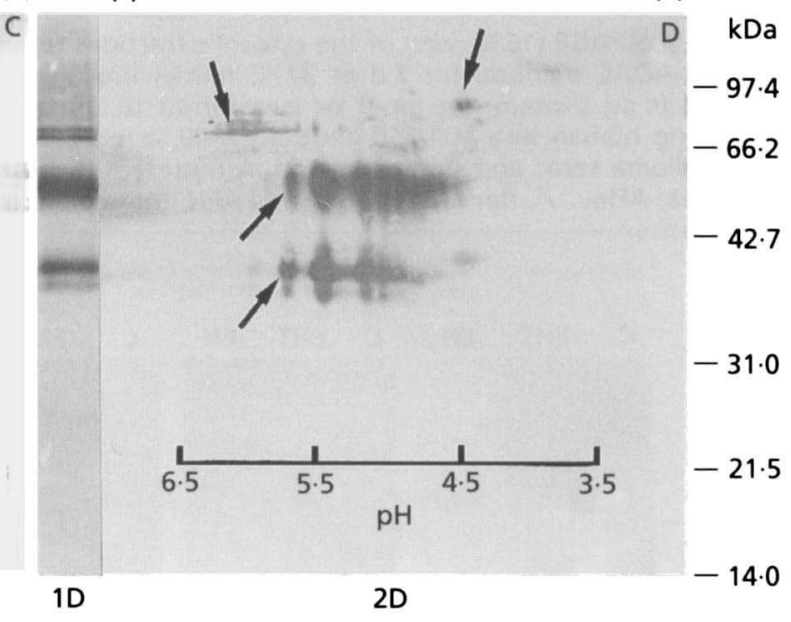

Fig. 3. SDS-PAGE (1D, $20 \mu \mathrm{g}$ protein per lane) and two-dimensional electrophoresis (2D, $500 \mu \mathrm{g}$ protein per gel) of the cytosolic fractions of three different $A$. fumigatus isolates. The 1D and 2D gels in panels A, B and C (isolates AFN, AFC and $A F R$, respectively) were silver-stained. Panel $D$ is an immunoblot of a $2 D$ gel, identical to the one shown in panel $C$ (isolate AFR), developed with a pool of four representative human aspergilloma sera (1/250); arrows indicate corresponding zones between the gel and the blot. CA, carbamylated carbonic anhydrase markers used as internal standard.

four bands of the CFC and $37 \%$ recognized at least $\mathrm{p} 90$ (alone or with p60), giving a combined total of $90 \%$ recognition; $10 \%$ of the aspergilloma sera did not give any reaction. By comparison, $70 \%$ of the 50 controls ( 35 sera) were non-reactive and $30 \%$ (15 sera) slightly recognized p60 (Fig. 1, control serum). These data suggest that $\mathrm{p} 90$ could be a useful aspergilloma marker, and that p40 and p37 could indicate a stronger immunological response to the infection.

\section{All the CFC polypeptide components are glycosylated}

To test if the CFC components were glycopeptides, we followed a protocol for specific staining of glycoproteins, using a commercial kit (Boehringer-Mannheim). As shown in Fig. 2 (Glycoprotein stain, lane C), only p60 stained strongly; some extremely faint reactions were present around the rest of the CFC components (not visible in the figure). To confirm this point, we digested cytosolic extracts from the three isolates with an excess of endoglycosidase $\mathrm{H}$. The result of the digestion is shown in Fig. 2 (only for isolate AFR) after SDS-PAGE separation and silver staining or immunoblotting with a representative aspergilloma serum (H-29). The electrophoretic mobility of all the components of the CFC was faster after endoglycosidase $\mathrm{H}$ treatment (lanes EHT) as compared with the original cytosol (lanes $\mathrm{C}$ ). This result demonstrates that $\mathrm{p} 90, \mathrm{p} 60, \mathrm{p} 40$ and $\mathrm{p} 37$ are all glycoproteins with at least $N$-linked sugars. The low sensitivity of the commercial kit used was probably responsible for 
the lack of staining of $\mathrm{p} 90, \mathrm{p} 40$ and $\mathrm{p} 37$. The fact that $\mathrm{p} 60$ was still stained after Endo $\mathrm{H}$ treatment indicates either that not all the $\mathrm{N}$-linked sugars were removed or that $\mathrm{O}$ linked sugars existed in the molecule.

\section{Two-dimensional mapping of CFC glycopeptides}

We analysed the cytosolic extracts of the three $A$. fumigatus isolates by two-dimensional electrophoresis. First-dimension (isoelectricfocusing) separation was done in the presence of urea on a gradient of acid $\mathrm{pH}$ (based on a mixture of 3.5-5, 4-6 and 5-7 ampholites). The second dimension was achieved by SDS-PAGE on $16 \%(\mathrm{w} / \mathrm{v})$ polyacrylamide gels. Carbamylated carbonic anhydrase (Pharmacia) was used as an internal standard. Gels were either silver-stained or transferred to nitrocellulose and incubated with aspergilloma serum samples. Fig. 3 shows the virtual equivalence of the silver-stained maps of the cytosols from the three different isolates (AFN, AFC, AFR). By comparison with the one-dimensional SDSPAGE included as a reference to the left of each twodimensional gel it is evident that all the CFC components are not single polypeptides; rather, each of them consists of several isoforms (as confirmed by chemical or enzymic peptide mapping studies to be described elsewhere) of slightly different pI. p 60 showed at least 11 different forms and p40 and p37 at least eight. The pI of these three groups of glycoproteins was acidic and very similar. $\mathrm{p} 90$ behaved as a family of at least five glycoproteins with slightly less acidic pIs. All the isoforms of the three isolates were reactive with serum samples from the different aspergilloma patients (the immunoblot with $\mathrm{H}$ 29 is shown in panel D of Fig. 3 as an example).

\section{DISCUSSION}

Our previous study on the influence of media and time and temperature of growth on the detection of $A$. nidulans antigens (Calera et al., 1994) showed that the use of strictly controlled culture conditions in Czapek-AOAC medium, as recommended by Kurup \& Kumar (1991), provides antigenic preparations that are reactive with serum samples from aspergilloma patients. Here we applied an identical approach to compare the reactivity of antigenic extracts of some species of Aspergillus commonly involved in pathological situations. The results obtained indicate that $A$. fumigatus provided the strongest reactivity with aspergilloma serum samples. Four polypeptides (p90, p60, p40 and p37) were present in the cytosolic fractions of three different $A$. fumigatus isolates grown under strictly controlled conditions. These polypeptides reacted strongly and repetitively with serum samples from patients with aspergilloma. The level of recognition was similar to that described in the literature when other detector antigens were used (Kim et al., 1979; Calvanico et al., 1981; Fratamico \& Buckley, 1991). p90 was the most specific antigen, detected by a $90 \%$ of the aspergilloma serum samples and none of the controls. Only p 60 seems to be recognized by $30 \%$ of the control serum samples (including healthy subjects or patients affected by diseases unrelated to Aspergillus). Either the high degree of glycosylation of this antigen or the ubiquity of Aspergillus species, or both, could be responsible for this reactivity.

Two-dimensional analysis in combination with Western blotting with well-characterized human serum samples discloses the great complexity of the antigenic mixtures used and provides a powerful means to more accurately define the characteristics of the antigens described here. Some of these characteristics, mainly their acidic PI and glycoprotein nature, are in agreement with those of previously described antigens (Calvanico et al., 1981; Fratamico \& Buckley, 1991). In this respect, a direct comparison could be made between our silver-stained two-dimensional patterns and those described for CS and CS2 by Piechura et al. $(1983,1987)$ and Calvanico et al. (1981). However, we have directly shown the consistent reactivity of all the isoforms present in the cytosolic preparations with IgGs in the serum samples of aspergilloma patients. Additionally, our silver-stained SDSPAGE profiles are reminiscent of those obtained by Piechura et al. (1987) when they analysed $96 \mathrm{~h}$ old $A$. fumigatus mycelia or by Fratamico \& Buckley (1991), who analysed younger mycelial extracts of the same species. In this latter case, the immunoblots also coincide in the detection of a $58 \mathrm{kDa}$ (very close to $60 \mathrm{kDa}$ ) antigen. These two antigens are probably the same, the slight difference in size being due to the conditions of preparation. In our hands, around $30 \%$ of the control serum samples also recognized this antigen. For this reason, its value for the diagnosis of aspergilloma or invasive aspergillosis is at least doubtful.

The glycosylation of Aspergillus antigens has been reported on several occasions (for a review see Kurup \& Kumar, 1991). We have shown that at least part of the carbohydrate moiety of CFC antigens is $N$-linked. A similar result has been reported for an $88 \mathrm{kDa}$ antigen purified from $A$. fumigatus (Kobayashi et al., 1993). Owing to differences in subcellular location, $\mathrm{pI}$ and reactivity with candidiasis serum samples (unpublished results) no relationship seems to exist between this antigen and the one described by us as $\mathrm{p} 90$.

The reason for the $\mathrm{pI}$ differences between the isoforms of the described antigens is not clear. They could be due to phosphorylation [the $58 \mathrm{kDa}$ antigen reported by Fratamico \& Buckley (1991) contained phosphate groups], sulfatation or differential glycosylation. Further work needs to be done to ascertain this point.

The CFC components still reacted with the aspergilloma sera after treatment with endoglycosidase $\mathrm{H}$. Total removal of the sugar from bands p90, p40 and p37 was demonstrated by gas-phase chromatography (unpublished results). These observations indicate that the immune recognition of these molecules seems to be due, at least in part, to their protein moiety. Similar results have been reported for other $A$. fumigatus antigens (Hearn et al., 1990; Kobayashi et al., 1993).

Our data indicate that $\mathrm{CFC}$ is an important antigenic complex of $A$. fumigatus, able to generate a strong antibody response in patients with aspergilloma. Owing 
to the high level of recognition of some of these antigens (especially p90) by human serum samples, they could be useful for the diagnosis of some forms of aspergillosis, mainly pulmonary aspergilloma.

\section{ACKNOWLEDGEMENTS}

We wish to thank Carlos Belinchón for photographic services, Drs M. Rivera and J. M. Torres-Rodríguez for providing the human serum samples, and Dr Ramón Santamaría for critical reading of the manuscript. We are grateful to Nicholas Skinner for revising the English manuscript. This work was supported by grant BIO92-0042 from the CICYT of the Ministerio de Educación y Ciencia (Spain). M. C. Ovejero and R. López Medrano are recipients of predoctoral fellowships from the Ministerio de Educación y Ciencia and the Fondo de Investigaciones Sanitarias de la Seguridad Social respectively.

\section{REFERENCES}

Andriole, V. T. (1992). Serodiagnosis of aspergillosis. In New Strategies in Fungal Disease, pp. 245-260. Edited by J. E. Bennet, R. J. Hay \& P. K. Peterson. Edinburgh: Churchill Livingstone.

Bravo, R. (1984). Two-dimensional gel electrophoresis: a guide for the beginner. In Two-dimensional Gel Electrophoresis of Proteins. Methods and Applications, pp. 3-36. Edited by J. E. Celis \& R. Bravo. Orlando, Florida: Academic Press.

Burnie, J. P., Matthews, R. C., Clark, I. \& Milne, L. J. R. (1989). Immunoblot fingerprinting Aspergillus fumigatus. J Immunol Methods 118, 179-186.

Calera, J. A., López-Medrano, R., Ovejero, M. C., Puente, P. \& Leal, F. (1994). Variability of Aspergillus nidulans antigens with media and time and temperature of growth. Infect Immun 62, 2322-2333.

Calvanico, N. J., Du Pont, B. L., Huang, C. J., Patterson, R., Fink, J. N. \& Kurup, V.P. (1981). Antigens of Aspergillus fumigatus. I. Purification of a cytoplasmic antigen reactive with sera of patients with Aspergillus-related disease. Clin Exp Immunol 45, 662-671.

Fratamico, P. M. \& Buckley, H. R. (1991). Identification and characterization of an immunodominant 58-kilodalton antigen of Aspergillus fumigatus recognized by sera of patients with invasive aspergillosis. Infect Immun 59, 309-315.

Hearn, V. M. (1992). Antigenicity of Aspergillus species. J Med Vet Mycol 30, 11-25.

Hearn, V. M., Wilson, E. V., Latgé, J. P. \& Mackenzie, D. W. R. (1990). Immunochemical studies of Aspergillus fumigatus mycelial antigens by polyacrylamide gel electrophoresis and Western blotting techniques. J Gen Microbiol 136, 1525-1535. van der Heide, S., Kauffman, H. F. \& de Vries, K. (1985a). Cultivation of fungi in synthetic and semi-synthetic liquid medium. I. Growth characteristics of the fungi and biochemical properties of the isolated antigenic material. Allergy 40, 586-591.

van der Heide, S., Kauffman, H. F. \& de Vries, K. (1985b). Cultivation of fungi in synthetic and semi-synthetic liquid medium. II. Immunochemical properties of the antigenic and allergenic extracts. Allergy 40, 592-598.

Kim, S. J. \& Chaparas, S. D. (1978). Characterization of antigens from Aspergillus fumigatus. I. Preparation of antigens from organisms grown in completely synthetic medium. Am Rev Respir Dis 118, 547-552.

Kim, S. J. \& Chaparas, S. D. (1979). Characterization of antigens from Aspergillus fumigatus. III. Comparison of antigenic relationships of clinically important Aspergilli. Am Rev Respir Dis 120, 1297-1303.

Kim, S. J., Chaparas, S. D. \& Buckley, H. R. (1979). Characterization of antigens from Aspergillus fumigatus. IV. Evaluation of commercial and experimental preparations and fractions in the detection of antibody in aspergillosis. Am Rev Respir Dis 120, 1305-1311.

Kobayashi, H., Debeaupuis, J. P., Bouchara, J. P. \& Latgé, J. P. (1993). An 88-kilodalton antigen secreted by Aspergillus fumigatus. Infect Immun 61, 4767-4771.

Kurup, V. P. \& Kumar, A. (1991). Immunodiagnosis of aspergillosis. Clin Microbiol Rev 4, 439-456.

Laemmli, U. K. (1970). Cleavage of structural proteins during the assembly of the head of bacteriophage T4. Nature 227, 680-685.

Latgé, J. P., Moutaouakil, M., Debeaupuis, J. P., Bouchara, J. P., Haynes, K. \& Prévost, M. C. (1991). The 18-kilodalton antigen secreted by Aspergillus fumigatus. Infect Immun 59, 2586-2594.

Morrisey, J. H. (1981). Silver stain for proteins in polyacrylamide gel: a modified procedure with enhanced uniform sensitivity. Anal Biochem 117, 307-310.

O'Farrell, P. H. (1975). High resolution two-dimensional electrophoresis of proteins. J Biol Chem 250, 4007-4021.

Peterson, G. L. (1977). A simplification of the protein assay method of Lowry et al. which is more generally applicable. Anal Biocbem 83, 346-356.

Piechura, J. E., Huang, C. J., Cohen, S. H., Kidd, J. M., Kurup, V. P. \& Calvanico, N. J. (1983). Antigens of Aspergillus fumigatus. II. Electrophoretic and clinical studies. Immunology 49, 657-665.

Piechura, J. E., Riefel, R. S. \& Daft, L. J. (1987). Electrophoretic and serological analyses of cytoplasmic antigens from Aspergillus fumigatus during growth of conidia to mature mycelia. $J$ Med Vet Mycol 25, 243-254.

Received 13 March 1995; revised 18 May 1995; accepted 5 June 1995. 